\title{
Driver training interests of a Spanish sample of young drivers and its relationship with their risky driving self-assessment skills.
}

\section{J. Gabriel Molina}

INTRAS, Universitat de Valencia (Spain)

E-mail: Gabriel.Molina@uv.es

\section{Jaime Sanmartín}

INTRAS, Universitat de Valencia (Spain)

E-mail: Jaime.Sanmartin@uv.es

\section{Esko Keskinen}

Department of Psychology, University of Turku (Finland)

E-mail: esko.keskinen@utu.fi

The final version of this paper was published in:

Molina, J. G., Sanmartín, J., \& Keskinen, E. (2013). Driver training interests of a Spanish sample of young drivers and its relationship with their self-assessment skills concerning risky driving behavior. Accident Analysis \& Prevention, 52, 118-124.

\begin{abstract}
This paper explores what competences are considered by the Spanish young drivers as more relevant to improve their current training as drivers as well as the relationship of these interests with their current risky driving self-assessment skills. For this purpose, a survey research design was planned with the Spanish young drivers (age between 18 and 24 years; no more than 4 years driving experience) as target population. From the initial near 1300-people sample invited to participate, we finally obtained complete data from 321 subjects. Measurement was based on participants' self-report of interests about contents to improve their driving, self-report of their risky driving behaviour, and self-assessment about their likelihood of being involved in a risky driving situation. Two main results arose from our data analysis: (1) novice drivers showed as their main interest to improve competences related to recognize their strengths and weaknesses as drivers (i.e., self-assessment skills); (2) a significant relationship between novice drivers' interests and their current risky driving self-assessment skills was found, more specifically, general interest about post-license training was higher for the under-confident self-assessors than for the over-confident ones. These results provide a relevant input to be taken into account in the design of driver training programs for novice drivers; moreover, the relationship between their training interests and their current risky driving self-assessment skills introduces an additional factor to be considered in the implementation of these training programs.
\end{abstract}

Keywords: Post-license driver training; driver's training interests; self-assessment skills 


\section{Introduction}

Road accidents are one of the main causes of death and injury among those aged under 25 in most developed countries (Clarke et al., 2005) and death rates for young men are often three times as high as those for young women (OECD, 2006). Although young drivers may show deficits in driving skills when compared with older drivers, accidents involving young drivers are frequently associated with voluntary risk-taking (Ferguson, 2003). The literature has provided several explanations for young drivers' accident involvement. One of these explanations is that drivers are overconfident in their own skills (Gregersen \& Bjurulf, 1996; OECD, 2006). It has been shown that young drivers with above-average driving skills have a high rate of accident involvement due to intentional risky behaviour and decisions, including speeding, drink driving and reckless or negligent driving (Clarke et al., 2005). Whilst young drivers seem to understand which behaviors are risky and tend to recognize their age group as a high-risk road user group, they do not consider themselves as risky drivers (Finn \& Bragg, 1986; Guerin, 1994). Moreover, young drivers typically assess themselves as more skilled and less likely to have an accident than their peers (Horswill et al., 2004; McKenna, 1993; McKenna et al., 2006). The capability of making an accurate assessment of one's own driving skills, though, is of great importance in driver's regulation of his/her driving behaviour (Hatakka et al., 2002).

This unrealistic optimism or tendency to optimism (Weinstein, 1980) has been investigated in the context of road safety since the early 1980s. It has been consistently found that drivers are considered in relation to their peers as more skilled in general (Delhomme, 1991; Delhomme \& Meyer, 2004), but also in specific driving tasks (Horswill et al., 2004), and less likely to have an accident (DeJoy, 1992; Gosselin et al., 2010; Harré et al., 2005). The optimism bias can lead to feelings of invulnerability (McKenna, 1993), founding that higher perceptions of driving skills were associated with lower perceptions of accident risk (Harré et al., 2005). Risk perception involves not only an assessment of the potential hazards in the traffic environment, but also an assessment of the driver abilities and the vehicle to prevent potential hazards from becoming actual crashes (Brown \& Groeger, 1988). Only a small fraction of the potential hazards represents any real danger for a driver in any given situation, but a more experienced driver will better be able to quantify the degree of a given danger and respond appropriately (Ferguson, 2003).

Adapting the behaviour to the task demands requires an accurate assessment of one's own driving skills and the complexity of the situation (Sundström, 2011). If the self-assessment is inaccurate, the driver might engage in driving tasks that are too demanding and unsafe (De Craen et al., 2011). On the other hand, the reduction of the optimism related to skill estimates and the accident risk in young drivers can lead to the adoption of safer driving behaviors (Klein, 1997; Mynttinen, 2010). Training based interventions that provide drivers with knowledge and experience, particularly insight-based forms of training, have also been associated with other positive outcomes in young drivers, such as decreased self-reported risky behaviors (McKenna et al., 2006) and increased hazard perception skills (Isler, Starkey \& Williamson, 2009). Partial support has been found for the effectiveness of accountability interventions in reducing the optimism bias: the accountability manipulation (i.e., making the drivers more 'accountable' for their ability estimates by inducing anticipation of being later evaluated on such abilities) effectively decreased skill perceptions but 
did not increase accident risk perceptions (McKenna \& Myers, 1997). It has also found that for accountability manipulations to be effective at reducing the optimism bias, participants must perceive the evaluator's status to be relevant and the assessment to be rigorous (Sedikides et al., 2002). Other findings suggest that the accountability manipulation could be effective in reducing the accident risk related optimism bias in very inexperienced drivers only (White et al., 2011).

The formulation of the GDE (Goals for Driving Education) framework has emphasized the importance of recognizing risk increasing factors, individual and social circumstances, and drivers' self-control and self-assessment skills (Hatakka et al., 2002). In fact, as the benefits of considering self-assessment skills in the training of drivers has been increasingly acknowledged, some European countries have undertook the redesign of their driving courses and testing procedures, incorporating educational goals in their driver education systems that state that drivers should develop a realistic view of their own skills as a driver (Boccara et al., 2011; Sundström, 2009; Twisk and Stacey, 2007). The redesign of these courses should take into account what training aspects drivers, especially young drivers, consider as more important to improve the training they have received to drive (MERIT, 2005). In fact, these interests would reflect what driving competences they consider are the main weaknesses of their driver training. Thus, the main aim of this work was to survey what competences are considered by young drivers as more relevant to improve their current training as drivers. The design of this survey was based on the GDE framework given that this driver training model considers not only operative and tactical driving competences but also personal competences like selfassessment skills. On other hand, we also aimed to analyze the relationship of young drivers' reported training interests and their actual risky driving self-assessment skills given that, if significant, the latter should be considered as a relevant input in the design of driver training programs for novice drivers.

\section{Method}

\subsection{Participants}

Participants included drivers associated to RACC, an Automobile Club with more than one million of members all around Spain. Three conditions were set to be able to take part in this study: age between 18 and 24 years; no more than 4 years driving experience; and residence in Madrid, Barcelona, Valencia, or towns surrounding these 3 large cities. These conditions were set because this sample was also thought to participate in other research project oriented to evaluate a post-license training programme for novice drivers, however, the survey oriented to gather the information of interest for us took place before this training programme was set in motion. Almost 5800 subjects satisfied the above 3 requirements, which served as the initial database from which were randomly selected 1296 candidates to be invited to participate. This selection was undertaken according to a sampling design blocked by age, sex and place of residence, and a target sample of 36 subjects for each of 36 cells $(6 \times 2 \times 3)$ of the blocked sampling design. Finally, 621 subjects agreed to participate in our study; however, some of them did not finally filled out or send back the questionnaires to us. In the end, we gained information for the variables of interest for 331 subjects, namely $25.5 \%$ of the original target sample and $53.3 \%$ of the subjects who initially agreed to participate. Because of 
sampling design, the distribution of females and males in the sample was very similar $(51.1 \%$ and $48.9 \%$, respectively) and the size of the age groups was rather balanced: it ranged between $14.5 \%$ for the groups of age 19 and 21, and $18.7 \%$ for the group of age 24 . The mean age in the male and female groups was 21.4 and 21.8 years, respectively.

\subsection{Measures}

Criteria measures in our study consisted of five scales. Three of these asked for subjects' interests to improve their driving with regard to the three main areas of the driving instruction raised in the GDE framework (Hatakka et al., 2002). They were: Scale TI-A, a 9-item scale of training interests related to knowledge and skills required to be a good driver; Scale $T I-B$, a 10-item scale of training motivations concerning the ability to recognize and avoid risk-enhancing factors; and Scale $T I-C$, a 9-item scale of training interests related to the ability to self-assess one's strengths and weaknesses as a driver. The statement for these 38 items can be read in Table 1. All the items were headed by the following statement: "If you were interested in taking training to improve your driving, to what extent would you be interested in the following aspects?". The response scale was the same for all the items in the 3 scales: 1 , "Not at all interested"; 2, "Not really interested"; 3, "Fairly interested"; 4, "Interested"; 5, "Very interested".

The other two scales, which were based on the work of Hatakka (1998) and Molina et al. (2007), asked for the subject's risky driving behaviour. They were: (1) Scale RD-SR (Self-Report of Risky Driving behaviour), a 15-item self-report scale of risky driving habits like driving in an improper state (DUI, tiredness, anger, stress), driving with high speed, competing, and showing-off (see Appendix A). The response scale for this scale ranged from 1 ("Never") to 5 ("Very often"). (2) Scale RD-SA (SelfAssessment about the likelihood of being involved in a Risky Driving situation): a self-assessment scale with 14 items asking about how likely the driver estimates that a number of personal driving conditions can get him/her into a risky situation. The driving conditions included classical risk driving factors like those considered in the $R D-S R$ scale (see Appendix B). The response scale for the $R D-S A$ scale ranged from 1 ("Highly unlikely") to 5 ("Very likely").

\subsection{Procedure}

In order to achieve our survey research design, we sent an introduction letter to the near 1300-people random sample selected from the RACC database as candidates to participate in our study. The letter described who we were, the purpose of our research, and raised an invitation to participate. It also announced an upcoming telephone call by RACC, which was planned in order to verify the reception of the first letter, remember its contents, solve possible doubts, and confirm whether or not the subject had decided to participate. For those who gave a positive answer $(\mathrm{N}=621)$, we sent a second letter which included the questionnaire and instructions to fill it out and send it back to us. One month after having sent this letter, a reminder phone call was carried out for those who had not sent us the questionnaire yet. 
The data gathered from the 331 participants that finally filled out the questionnaire was first analyzed in order to clean up the collected data. Four main strategies were applied to explore for potential pitfalls in the data processing phase as well as for strange subject response patters: (1) anomalous values in frequency distributions, cross-tabulations, summary statistics, and uni- and bi- variate graphical representations; (2) subject's very low response rates; (3) extreme standardized means and standard deviations of the subject's response patterns (Dolinger \& Dilalla, 1996), and (4) inconsistencies in the subject's expected responses to specific pairs of items. While the first method is variable-oriented and provided information that served either to correct some specific values or to recode them as missing, the other 3 methods are case-oriented, providing support to locate missing or inconsistent response patterns. According to this preliminary analysis, data records of 12 subjects were removed from the database so the final sample size in the subsequent analysis was 319 .

\section{Results and discussion}

Results are presented in two blocks: The first one concerns the data analysis related to the participants' interests in a number of driver training contents, whereas the results related to the relation of these training interests with a construct raised to measure self-assessment skills related to risk perception are presented in a second block.

\subsection{Driving contents training interests}

The main results of the item-level analysis of the participants' interests are shown in Table 1, where the scale items of $T I-A, T I-B$ and $T I-C$ have been ordered within each scale according to the participants' stated interests (the higher the mean, the more interest in that driving content). The two last columns in Table 1 are oriented to make easier the global comparison of all the items given that they show total results, without differentiating by block of training content: the Z-Mean column includes the standardized means obtained after subtracting to each mean the total mean (3.73) and dividing by the standard deviation of the means (0.36); and the last column includes a symbolic transformation of the standardized means into ten categories which range from $\times \times \times \times \times(Z$-mean $<-2$, that is, very low interest on this training content) to $\checkmark \checkmark \checkmark \checkmark \checkmark(Z$-mean $>2$, that is, very high interest on it). 
Table 1: Young drivers' interests concerning contents of driver training.

$N$ Mean SD Z-Mean

\section{A. Knowledge/skills concerning:}

1 Adapting the position of the driver and the car (seating, mirrors, headrests...)

2 How other drivers and passengers can influence your own driving

3 How our lifestyle can affect our driving style

4 Driving at appropriate speed according to traffic situations

5 Carrying out different types of maneuvers (parking, reversing, ramps...)

6 How to recognize traffic situations which are really important

7 Visual awareness of the traffic situation outside the vehicle

$\begin{array}{ccccc}316 & 2.91 & 1.12 & -2.27 & \times \times \times \times \times \\ 317 & 3.32 & 1.11 & -1.14 & \times \times \times \\ 316 & 3.42 & 1.10 & -0.84 & \times \times \\ 317 & 3.50 & .96 & -0.64 & \times \times \\ 316 & 3.50 & 1.13 & -0.63 & \times \times \\ 317 & 3.61 & .90 & -0.32 & \times \\ 316 & 3.81 & .93 & 0.24 & \checkmark \\ 315 & 3.83 & 1.07 & 0.30 & \checkmark \\ 315 & 3.85 & .99 & 0.35 & \checkmark\end{array}$

\section{B. Recognizing and avoiding enhancing-risk factors like:}

1 Drink driving or under the influence of other "drugs"

2 Some personal habits can cause distractions (cell phoning, smoking...)

3 A poor steering technique

4 Driving in traffic jams

5 Driving while distracted or thinking about other things

6 Driving in a hurry to get somewhere

7 The presence of cyclists and pedestrians in the street

8 Driving while tired

9 Distraction of other drivers

10 Speeding

$\begin{array}{ccccc}316 & 3.37 & 1.25 & -0.98 & \times x \\ 316 & 3.46 & 1.19 & -0.75 & \times x \\ 316 & 3.50 & 1.03 & -0.62 & \times x \\ 315 & 3.53 & 1.04 & -0.55 & \times x \\ 315 & 3.58 & 1.02 & -0.42 & \times \\ 314 & 3.66 & 1.09 & -0.18 & \times \\ 316 & 3.68 & .97 & -0.14 & \times \\ 316 & 3.76 & 1.04 & 0.10 & \checkmark \\ 315 & 3.79 & 1.00 & 0.18 & \checkmark \\ 315 & 3.81 & 1.00 & 0.22 & \checkmark\end{array}$

\section{Ability to recognize one's strengths and weaknesses concerning:}

1 Your knowledge of traffic norms and signs

\begin{tabular}{ccccc}
317 & 3.38 & 1.09 & -0.95 & $x \times$ \\
317 & 3.69 & 1.05 & -0.10 & $x$ \\
316 & 3.82 & .92 & 0.25 & $\checkmark$ \\
317 & 3.84 & .94 & 0.31 & $\checkmark$ \\
317 & 4.05 & .94 & 0.91 & $\checkmark \checkmark$ \\
317 & 4.21 & .78 & 1.34 & $\checkmark \checkmark \checkmark$ \\
317 & 4.44 & .75 & 1.98 & $\checkmark \checkmark \checkmark \checkmark$ \\
317 & 4.48 & .73 & 2.10 & $\checkmark \checkmark \checkmark \checkmark \checkmark$ \\
317 & 4.54 & .71 & 2.27 & $\checkmark \checkmark \checkmark \checkmark \checkmark$ \\
\hline
\end{tabular}

2 An ability to plan a journey (route, timing, breaks...)

3 Attitudes toward traffic safety

4 Respect of safety margins (from those in front and when overtaking)

5 Personal tendency to take risks

6 Visually scanning what is happening around the vehicle

7 Your ability to brake in different surface conditions

8 An ability to anticipate dangerous situations when driving

Response scale for all the items ranged from 1 ("Not at all interested") to 5 ("Very interested").

Some trends rise from the visualization of the data analysis results shown in Table 1:

(1) The training contents items deserving less attention by the participants were those related to getting knowledge and skills about a set of typical driving topics (average mean $=3.53$ ). Thus, scale $T I-A$ contains an item with an extremely low $Z$-mean score $(Z=-2.27)$, something not very surprising taking into account that it is related to a very basic driving competence that it is supposed to be mastered by most young drivers participating in the study.

(2) Items concerning the training on the ability to recognize and avoid driving risk factors appear to be located in a middle range (average mean $=3.62$ ). The mean $\mathrm{Z}$-scores of the items in scale $T I-B$ fluctuate between -0.98 and 0.22 , being the three most valued items those related to driving while tired, other's distractions, and speeding. 
(3) Most items in the scale $T I-C$, the ones related to the training of self-assessment abilities skills (i.e., finding out how good you are in recognizing your strengths and weaknesses), were considered by the participants as the most interesting contents to be improved in their training as drivers (average mean $=$ 4.05). The most significant exception is the item related to the self-assessment of knowledge of traffic norms and signs, which has a Z-mean score close to -1 .

\subsection{Analysis of the relationship between the participants' training interests and their risky driving} self-assessment skills.

For the first construct of this relationship, we decided to work with the participants' total mean scores in each one of the three scales of training contents interests considered in this study ( $T I-A, T I-B$ and $T I-C)$. Thus, we proceeded to check the psychometric properties of these scales by means of the analysis of the dimensional structure and reliability of the test scores derived from them. Analysis of dimensionality was achieved through the application of the Principal Components Analysis model to the response data sets collected from $T I-A, T I-B$ and $T I-C$. The results of the factor extraction showed that the three scales had a mainly unidimensional factor structure: the scree plots for the three factorial solutions displayed as the elbow in the chart lines appeared for the second principal component ( $\%$ of variance explained by the first and second components was 43.5 and 12.1 in the scale $T I-A, 50.1$ and 9.4 in the scale $T I-B$, and 51.6 and 12.9 in the scale $T I-C$ ). Reliability analysis of the scale scores was based on the computation of Cronbach's alpha: the results were 0.84 for scale $T I-A, 0.89$ for scale $T I-B$, and 0.88 for scale $T I-C$, values which reflected a considerable high internal consistency for the three scales. Thus, both dimensional and reliability analysis provided empirical support to use, in the succeeding analysis, the scores obtained from the scales $T I-A, T I-B$ and $T I-C$.

We needed, though, to raise an indicator of the second construct involved in our correlation analysis, that is, how realistic are the drivers when assessing their own risky driving behaviour. For this purpose, we used the participants' scores in both the scale $R D-S R$ (self-report of risky driving habits) and the scale $R D$ $S A$ (self-assessment of the likelihood of being involved in a risky driving situation). Given that risky driving habits are related to a higher likelihood of getting involved in driving trouble, it was supposed that scores in the $R D-S R$ scale would be related to scores in the $R D-S A$ scale in a linear, positive way. This hypothesized direct relationship was confirmed through the visualization of their bivariate distribution (see scatterplot in Figure 1, left) as well as the computation of the product-moment correlation of both variables $\left(r_{X Y}=.62, p<\right.$ $.001)$.

This relationship between $R D-S R$ and $R D-S A$ was the basis to raise an index of Self-Assessment Skills related to Risky Driving ( $R D-S A S)$. Thus, taking the linear regression estimated equation for the bivariate distribution of variables $R D-S R$ and $R D-S A$ as the reference line for a fair self-assessment, subjects' residual scores $\left(Y_{i}-Y^{\prime}\right)$ would provide an indicator of their self-assessment skills related to risky driving $(R D-S A S)$ : the closer subjects' residuals to $0(R D-S A S \approx 0)$ are, the better their ability to assess in a realistic way the likelihood of being involved in a risky driving situation will be; on the other hand, the farther from zero, 
whether positive or negative, the less accurate their self-assessment skills will be. We may differentiate, however, between two types of poorly skilled self-assessing drivers: (1) those who have positive residual scores $(R D-S A S>0)$ and, therefore, estimate the likelihood of getting into a risky situation as higher than they should, taking into account their driving habits (i.e., under-confident self-assessment); (2) on the opposite, the participants with negative residual scores $(R D-S A S<0)$ would show the reverse trend, estimating their likelihood of getting into a risky situation as lower than they should (i.e., over-confident self-assessment). Both types of unrealistic self-assessment will be more marked when the $R D-S A S$ score (i.e., the residual score) is higher in absolute value.
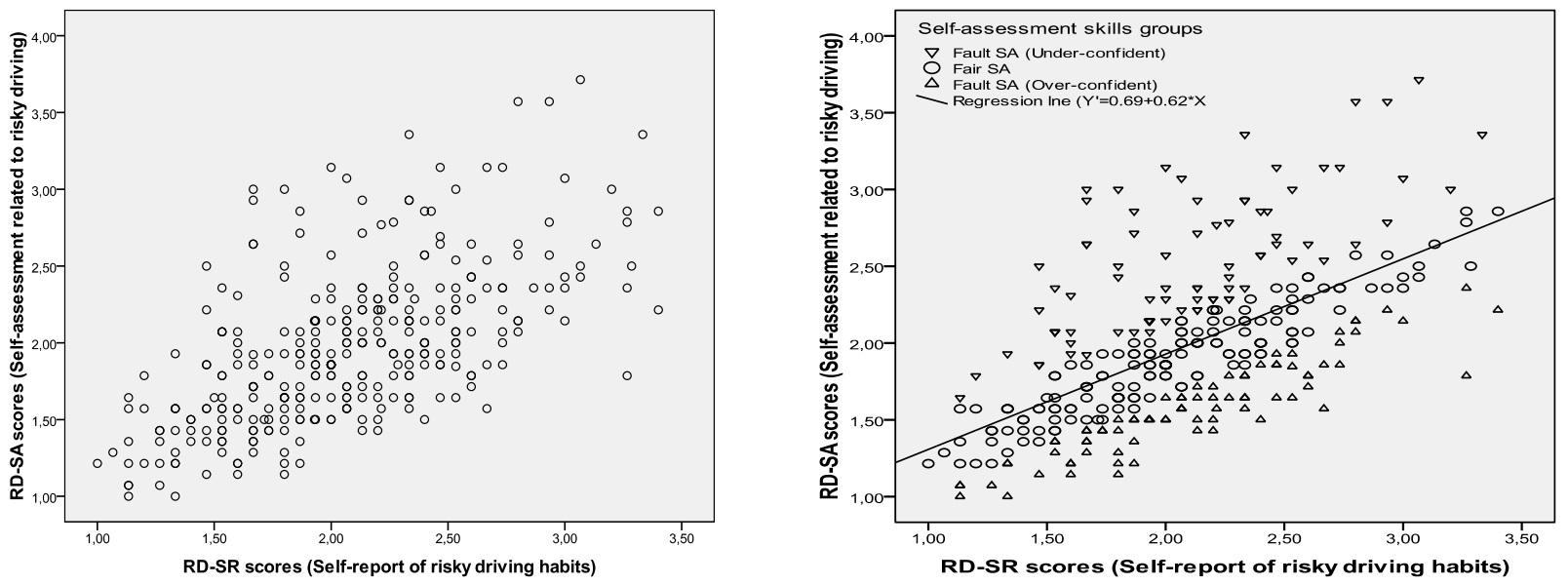

Fig. 1. Novice drivers' self-reported risky driving habits $(R D-S R)$ compared to their self-assessed risky driving ( $R D-S A$ ): (left) Scatterplot of the standard scores of the $R D-S R$ and $R D-S A$ variables; (right) Ditto. grouped according to the regression residuals (Grouped $R D-S A S$ ). Response scale for all the items ranged from 1 (Not at all interested) to 5 (Very interested).

In the regression analysis oriented to compute the residual scores ( $R D-S A S$ variable) from our data, we also included the gender variable as a predictor in the model given the usually relevant role of this variable in road safety research, so the effect of this variable was kept statistically controlled. Actually, the results showed a statistically significant effect of the main predictor variable $(R D-S R) \mathrm{t}=13,6, S i g<.001$, as well as of the Gender variable, $t=-2,26$, Sig $=.024$. The interaction effect of both predictors was not statistically significant. Approximately $39 \%\left(R^{2}=.389\right)$ of the variance of the response variable $(R D-S A)$ was explained by the predictor variables $(R D-S R$ and Gender).

Once we had set a measure for the participants' self-assessment skills of their risky driving, we proceeded to analyze the relationship between this variable $(R D-S A S)$ and the interests in each one of the three blocks of driver training contents considered in this study. For this specific analysis, we first carried out the recodification of the $R D-S A S$ variable into three categories oriented to differentiate three potential groups of drivers according to their self-assessment skills: over-confident, fair, and under-confident self-assessors. The three groups of this new variable (Grouped $R D-S A S$ ) were set according to the standardized residuals of the regression analysis of $R D-S A$ over $R D-S R$ : the participants with a standardized residual lower than -.5 
were assigned to the over-confident self-assessment category, the participants with residuals between -.5 and .5 were assigned to the fair self-assessment category, whereas in the under-confident self-assessment category were included the participants with a standardized residual over .5 (see scatterplot on the right in Figure 1). With regression residuals normally distributed, this grouping criterion would provide an approximate 30/40/30 partition in the sample, which was intended to maximize the differences in the scores between the two groups with fault self-assessment skills, despite the drawback of the imbalanced size of the resulting groups.

In the analysis of the relationship between the participants' self-assessment skills and their training interests, an univariate ANOVA model was used to analyze the data of our mixed between-within design: the Grouped $R D-S A S$ variable was set as a between-subjects factors with 3 levels (over-confident, fair, under-confident), while the Driver training Contents variable was set as a within factor with 3 levels: the participants' scores in the 3 scales of driving contents training interests $(T I-A, T I-B$ and $T I-C)$. A factorial design was computed and all the omnibus hypotheses were treated as fixed effects in the analysis. Mauchly's test of sphericity was not significant ( $W=.99, p=.15$ ) so no correction of the degrees of freedom was applied in the ANOVA. The analysis results showed that, with an alpha level of .05, the interaction effect was not statistically significant, $(F(4,624)=.65, p=.63)$, however, the effect of self-assessment skills $(R D-S A S)$ on the training interests was statistically significant $\left(F(2,312)=4.18, p=.016, \eta^{2}=.03\right)$, in the same way as it was the effect of the type of driver training contents $\left(F(2,624)=127.7, p<.01, \eta^{2}=.29\right)$.

Figure 2 displays the means for all the conditions in our design, offering insight about the meaning of the analyzed pattern of relationships. Given that both Driver training Contents and Grouped RD-SAS variables had three levels, we computed post hoc comparisons with LSD tests to analyze the significant main effects obtained with the ANOVA. Post hoc analysis for the Driver training Contents variable showed statistically significant differences between interests in self-assessment related contents $(M=4.04)$ and riskfactors contents $(M=3.61), I C 95 \%(\delta)=[.36, .50]$, between risk-factors contents and knowledge and skills contents $(M=3.52), I C(.95)=[.03, .17]$, and, consequently, between self-assessment related contents and knowledge and skills contents, $I C 95 \%(\delta)=[.47, .60]$. On other hand, interest about post-license driver training, independently of the contents, was higher for the participants in the under-confident group ( $\mathrm{M}=$ 3.85), followed by the fair self-assessors $(M=3.72)$, and the over-confident ones $(M=3.58)$. In this case, post hoc analysis for the Grouped $R D-S A S$ variable only showed statistically significant differences between the under-confident group and the over-confident group, $\operatorname{IC} 95 \%(\delta)=[.09, .45]$. 


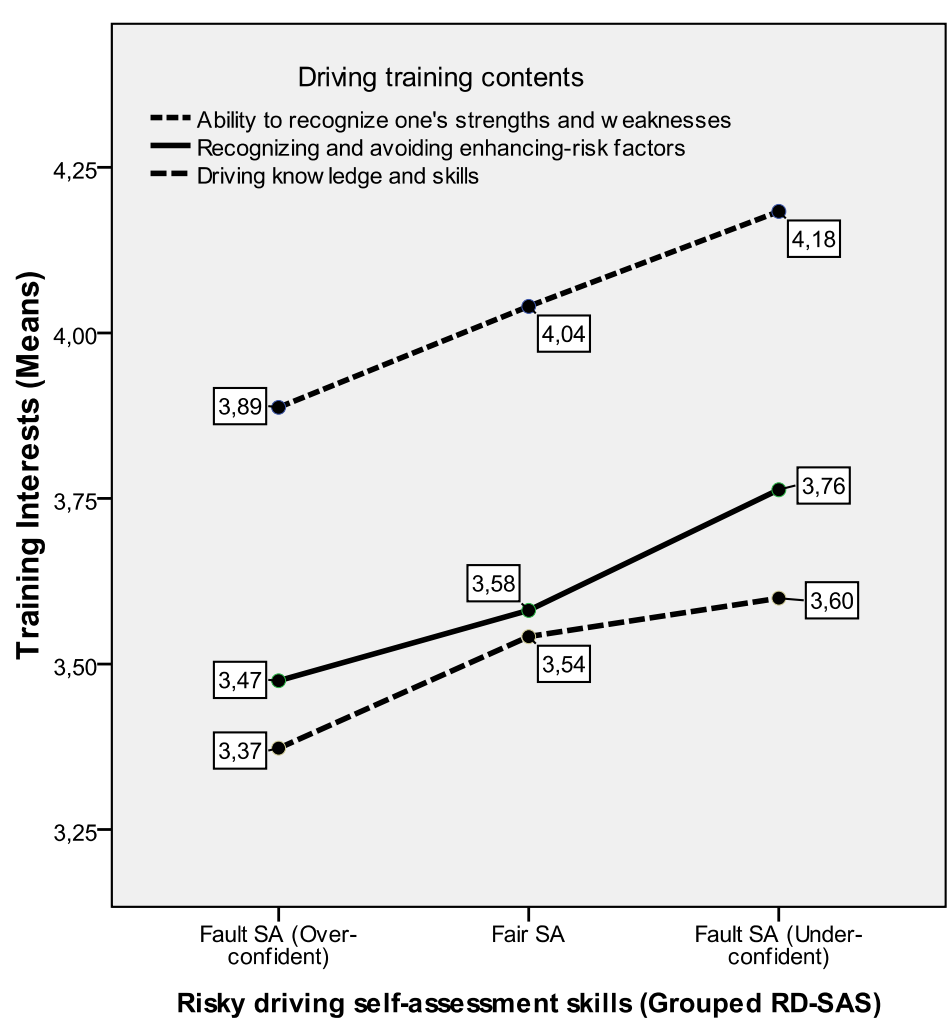

Fig. 2. Plot with the means of the participants' training interests according to the type of driver training contents and their self-assessment skills. Response scale for all the items ranged from 1 ("Not at all interested") to 5 ("Very interested").

\section{Conclusions}

The aim of this work was to analyze (1) what contents are considered by the Spanish young drivers as more relevant to improve their current training as drivers, and (2) the relationship of these interests with their risky driving self-assessment skills.

(1) The answer for the first question was clear: in their further education, young novice drivers preferred contents connected to their ability to recognize their strengths and weaknesses as drivers more than contents related to risk factors and basic driving skills/knowledge. Most items in the scale related to the training of the ability to recognize one's abilities as driver were considered by the participants as the most interesting contents to be improved in their driver education. The most significant exceptions in this selfassessment scale were the items related to the knowledge of traffic norms and signs and, partly, the item concerning the ability to plan a journey; however, the results, in general, can be seen as a positive finding taking into account the arguments supporting the idea that good driving self-assessment skills are an important part of safe driving habits (Eby et al., 2003; Gregersen, 1996; Sundström, 2011). These results may also reflect young persons' interest in knowing what kind of persons they are (i.e., what kind of skills they have, how competent they are), a common trait in the transition period from adolescence to adulthood (Boud, 1995; Stipek \& Mac Iver, 1989). 
The preferred self-assessment driving competences $($ Scale $T I-C)$ were those related to controlling the car in complex situations, braking in different surface conditions, risk anticipation, and visual scanning. These can be mainly described as driving competences focused on mastering driving situations as well as on basic operative driving skills (i.e., the lower levels of driving behaviour in the GDE framework). When looking at the two other scales, $T I-A$ and $T I-B$, we could see that the preferred contents in the former (knowledge and skills) were related to visual awareness of the traffic situation, vehicle positioning, and estimating braking distance, whereas the preferred ones in the latter (recognizing and avoiding enhancingrisk factors) were contents concerning driving while tired, distraction of other drivers, and speeding. Again, contents of interest in both scales concentrated on the first and second levels of the driver behaviour hierarchy set by the GDE framework. This result may reflect novice drivers' understanding that driving focuses on tactical and operative competences, which is a classical view in driving school education (Keskinen \& Hernetkoski, 2011), whereas other aspects concerning decisions related to the context of driving (e.g., when to drive, with whom), planning of the trip (e.g., driving route, driving time), and the influence of personal factors (e.g., lifestyle, motivations, attitudes) on one's driving behaviour are considered as less significant in their training.

(2) The results concerning the relationship between novice drivers' interests and their actual risky driving self-assessment skills were also clear: interest concerning post-license driver training, independently of the contents, was higher for the participants in the under-confident group, followed by the fair selfassessors, and the over-confident ones, yet statistically significant differences were only found for the under-confident and the over-confident groups. This is what could be expected on the basis of earlier findings (i.e., those who are more interested in taking further education in safe driving are the ones who, actually, are more cautious and safety minded), however, it rises an important challenge when it comes to set a successful advanced training for novice drivers: on the one hand, in the case of the under-confidents drivers, improving their driving basic skills is likely not going to increase their self-confidence, which may be more related to improving their self-assessment skills so that their perceived driving risk went down to become equated with which actually are their driving habits; on the other side, advanced training for the over-confident drivers should also consider improving their self- assessment skills, yet in the opposite sense to these of the under-confidents drivers. An added difficulty to be considered in the training of the overconfident drivers is their lower interest about taking further training, although an important result derived of our study is that for all the participants, including the over-confident drivers, the more requested driving competences were these related to the improvement of the ability to self-assess one's strengths and weaknesses as driver, an important fact when it comes to tackle the improvement of the self-assessment skills of these drivers.

Limitations of the study: it must be noted that all the participants had volunteered to get a safe driving course and because of that, they might be more interested in increasing their safe driving competences than those who were invited and refused. Another limitation to the external validity of this study is that all the participants were from Spain so they had a common driving background coming from the unified guidelines and curriculum of the Spanish driving school system. 


\section{Acknowledgments}

The authors express their sincere gratitude to the Real Automobil Club de Barcelona (RACC), which provided the financial and logistic support to the development of this research. Mr. Pere Sauret, Mr. Albert Alumà and Mr. Lluis Puerto, from RACC, were especially involved in this research project. We would also like to express our gratitude to Nick Sanders for his helpful support to this study. 


\section{Appendix A. Scale RD-SR}

We would now like to present to you a list of driving-related circumstances and situations. Estimate how often they happen to you. For each situation, make an $\mathrm{X}$ on a value between 1-5 according to the following scale:

\section{Never 2. Seldom 3. Every now and then 4. Often 5. Very often}

1 Driving while tense or nervous

2 Driving quicker than normal when in a hurry

3 Driving after having drunk a few too many

4 Other drivers have challenged me

5 Thinking of that speed limits are mostly very restrictive

6 Driving too close to the car in front

7 Driving when tired

8 Competing with other drivers

9 Driving too quickly according to the traffic conditions (poor visibility, presence of pedestrians, slippery road)

10 Getting angry with another driver who overtakes me

11 Approaching a junction at too high speed

12 Taking the car out for a drive to relax after having had a problem

13 Driving in a more risky way to get in time somewhere.

14 Getting angry with the car driver in front because he is travelling slower

15 Driving more than $20 \mathrm{kmh}$ over the speed limit

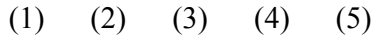

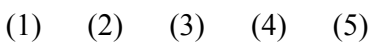

$\begin{array}{llll}(1) & (2) \quad(3) \quad(4) \quad(5)\end{array}$

$\begin{array}{llll}(1) & (2) \quad(3) \quad(4) \quad(5)\end{array}$

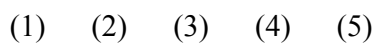

$\begin{array}{llll}(1) \quad \text { (2) (3) (4) (5) } & \text { (1) }\end{array}$

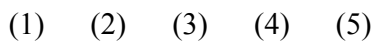

(1) (2) (3) (4) (5)

(1) (2) (3) (4) (5)

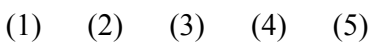

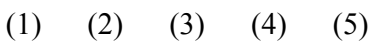

$\begin{array}{llll}(1) & \text { (2) (3) (4) (5) }\end{array}$

$\begin{array}{llll}(1) \quad \text { (2) (3) (4) (5) } & \text { (3) }\end{array}$

$\begin{array}{llll}(1) \quad \text { (2) (3) (4) (5) } & \text { (3) }\end{array}$

(1) (2) (3) (4) (5)

\section{Appendix B. Scale RD-SA}

Moving on, a series of aspects related to character, habits and skills is presented below. These aspects could give rise to certain risky situations when driving. For each of these statements, please make an $\mathrm{X}$ on a value between 1-4 according to what extent you think they could get you into a risky situation.

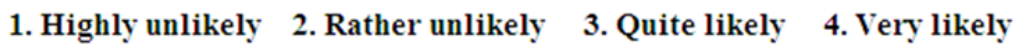

1 Falling asleep while driving

2 Enjoying driving fast

3 Carelessness or distraction

4 Playing with the car

5 Taking the car out being excited or nervous because some reason

6 Ignorance of certain traffic rules

7 Getting nervous easily while driving

8 Enjoying showing off ones driving skills to others

9 Willingness to take risks

10 Getting easily annoyed by other road users

11 Driving too close to the car in front

12 Driving under the influence of alcohol (or similar)

13 Willingness to compete in traffic

14 Overconfidence in my driving ability

$\begin{array}{llll}(1) & (2) & (3) & (4) \\ (1) & (2) & (3) & (4) \\ (1) & (2) & (3) & (4) \\ (1) & (2) & (3) & (4) \\ (1) & (2) & (3) & (4) \\ (1) & (2) & (3) & (4) \\ (1) & (2) & (3) & (4) \\ (1) & (2) & (3) & (4) \\ (1) & (2) & (3) & (4) \\ (1) & (2) & (3) & (4) \\ (1) & (2) & (3) & (4) \\ (1) & (2) & (3) & (4) \\ (1) & (2) & (3) & (4) \\ (1) & (2) & (3) & (4)\end{array}$




\section{References}

Boccara, V., Delhomme, P., Vidal-Gomel, C., Rogalski, J., 2011. Development of student drivers' self-assessment accuracy during French driver training: Self-assessments compared to instructors' assessments in three risky driving situations. Accident Analysis \& Prevention 43, 1488-1496.

Boud, D., 1995. Enhancing learning through self-assessment. Kogan Page, London.

Brown, I.D., Groeger, J.A., 1988. Risk perception and decision taking during the transition between novice and experienced driver status. Ergonomics 31, 585-597.

Clarke, D.D., Forsyth, R., Wright, R., 2005. A statistical profile of road accidents during cross-flow turns. Accident Analysis \& Prevention 37, 721-730.

Clarke, D.D., Ward, P., Truman, W., 2005. Voluntary risk taking and skill deficits in young driver accidents in the UK. Accident Analysis \& Prevention 37, 523-529.

De Craen, S., Twisk, D.A., M., Hagenzieker, M.P., Elffers, H., Brookhuis, K.A., 2011. Do young novice drivers overestimate their driving skills? Different methods lead to different conclusions. Accident Analysis \& Prevention 43, 1660-1665.

DeJoy, D.M., 1992. An examination of gender differences in traffic accident risk perception. Accident Analysis \& Prevention 24, 237-246.

Delhomme, P., 1991. Comparing one's driving with others': assessment of abilities and frequency of offences. Evidence for a superior conformity of self-bias? Accident Analysis \& Prevention 23, 493-508.

Delhomme, P., Meyer, T., 2004. Risk taking and self-efficacy among young male driver: self-efficacy and changing task demands. In T. Rothengatter \& R.D. Huguenin (Eds.), Traffic and transport psychology: Theory and application (pp. 135-146). Elsevier, Amsterdam.

Dolinger, S.J., Dilalla, D.L., 1996. Cleaning up data and running preliminary analyses. In Frederick T. Leong \& James T. Austin (Eds.): The Psychology Research Handbook. A Guide for Graduate Students and Research Assistants. Sage, Thousand Oaks.

Eby, D.W., Molnar, L.J., Shope, J.T., Vivoda, J.M., Fordyce, T.A., 2003. Improving older driver knowledge and awareness through self-assessment: The driving decisions workbook. Journal of Safety Research 34, 371-381.

Ferguson, S., 2003. Other high-risk factors for young drivers - How graduated licensing does, doesn't, or could address them. Journal of Safety Research 34, 71-77.

Finn, P., Bragg, B.W., 1986. Perception of the risk of an accident by young and older drivers. Accident Analysis \& Prevention 18, 289-298.

Gosselin, D., Gagnon, S., Stinchcombe, A., Joanisse, M., 2010. Comparative optimism among drivers: an intergenerational portrait. Accident Analysis \& Prevention 42, 734-740.

Gregersen, N.P., 1996. Young car drivers: Why are they overrepresented in traffic accidents? How can driver training improve their situation? (VTI report n. 409). Swedish National Road and Transport Research Institute, Linköping.

Gregersen, N.P., Bjurulf, P., 1996. Young novice drivers: Towards a model of their accident involvement. Accident Analysis and Prevention 28, 229-241.

Guerin, B., 1994. What do people think about the risks of driving? Implications for traffic safety interventions. Journal of Applied Social Psychology 24, 994-1021.

Harré, N., Foster, S., O’Neill, M., 2005. Self-enhancement, crash-risk optimism and the impact of safety advertisements on young drivers. British Journal of Psychology 96, 215-230. 
Hatakka, M., 1998. Novice Drivers' Risk- and Self-Evaluations (Doctoral Thesis). Annales Universitatis Turkuensis, ser. B - TOM. 228. Turku, University of Turku, Finland.

Hatakka, M., Keskinen, E., Gregersen, N.P., Glad, A., Hernetkoski, K., 2002. From control of the vehicle to personal self-control: broadening the perspectives to driver education. Transportation Research Part F: Traffic Psychology and Behaviour 5, 201-215.

Horswill, M.S., Waylen, A.E., Tofield, M.I., 2004. Drivers' ratings of different components of their own driving skill: a greater illusion of superiority for skills that relate to accident involvement. Journal of Applied Social Psychology 34, 177-195.

Isler, R.B., Starkey, N.J., Williamson, A.R., 2009. Video-based road commentary training improves hazard perception of young drivers in a dual task. Accident Analysis and Prevention 41, 445-452.

Keskinen, E., Hernetkoski, K., 2011. Driver education and training. In Bryan E. Porter (Ed.), Handbook of traffic psychology..Elsevier, Amsterdam.

Klein, W.M., 1997. Objective standards are not enough: affective, self-evaluative and behavioral responses to social comparison information. Journal of Personality and Social Psychology 72, 763-774.

McKenna, F.P., 1993. It won’t happen to me: unrealistic optimism or illusion of control? British Journal of Psychology 84, 39-50.

McKenna, F.P., Horswill, M.S., Alexander, J.L., 2006. Does anticipation training affect drivers' risk taking? Journal of Experimental Psychology: Applied 12, 1-10.

McKenna, F.P., Myers, L.B., 1997. Illusory self-assessments. Can they be reduced? British Journal of Psychology 88 , 39-51.

MERIT, 2005. Minimum Requirements for Driving Instructor Training, MERIT EU Project Final Report, (EC Contract DG TREN: SER-B27020B-E3-2003). Institute Gute Fahrt, Vienna.

Molina, J.G., Sanmartín, J., Sanders, N., Keskinen, E., 2007. Post-license education for novice drivers: Evaluation of a training programme implemented in Spain. Journal of Safety Research 38, 357-366.

Mynttinen, S., 2010. Finnish novice drivers' competences- compared to the Swedish, Dutch and Austrian novices. (Doctoral dissertation). Trafi Publications, Finland.

OECD, 2006. Young drivers: The road to safety. OECD_Organisation for Economic Co-operation and Development \& ECMT-European Conference of Ministers of Transport. Paris, Joint OECD/ECMT Transport Research Centre.

Sedikides, C., Herbst, K.C., Hardin, D.P., Dardis, G.J., 2002. Accountability as a deterrent to self-enhancement: the search for mechanisms. Journal of Personality and Social Psychology 83, 592-605.

Stipek, D.J., Mac Iver, D., 1989. Developmental change in children's assessment of intellectual competence. Child Development 60, 521-538.

Sundström, A., 2009. Developing and validating self-report instruments. Assessing perceived driver competence (Academic Dissertations at the Department of Educational Measurement No. 5). Umeå University: Department of Educational Measurement.

Sundström, A., 2011. The validity of self-reported driver competence: Relations between measures of perceived driver competence and actual driving skill. Transportation Research Part F 14, 155-166.

Twisk, D., Stacey, C., 2007. Trends in young driver risks and countermeasures in European countries. Journal of Safety Research 38, 245-257.

Weinstein, N.D., 1980. Unrealistic optimism about future life events. Journal of Personality and Social Psychology 39 , 806-820. 
White, M.J., Cunningham, L.C., Titchener, K., 2011. Young drivers' optimism bias for accident risk and driving skill: Accountability and insight experience manipulations. Accident Analysis \& Prevention 43, 1309-1315. 